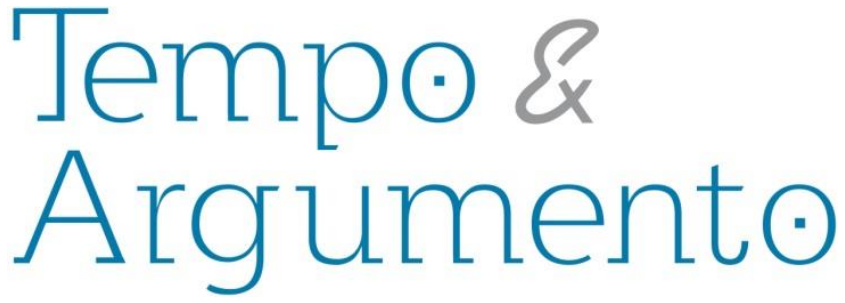

\title{
Canções, Projetos e Expressões Políticas
}

\section{Resenha da obra:}

VALENTE, Heloísa de A. Duarte; PEREIRA, Simone Luci. Com Som, Sem Som - Liberdade políticas, liberdades poéticas. São Paulo: Letra e Voz/FAPESP, 2016.

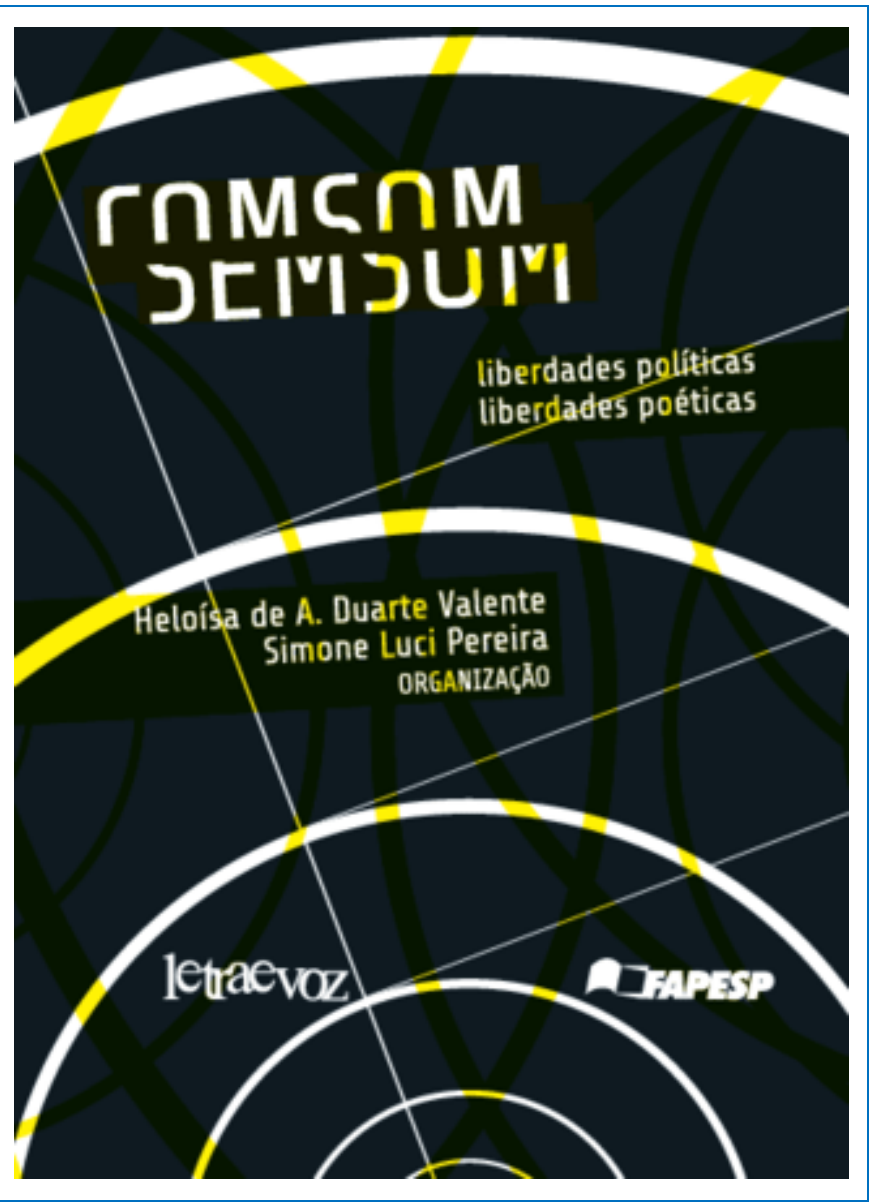

\section{Autor da resenha}

\section{Igor Lemos Moreira}

Mestrando no Programa de Pós-Graduação em História da Universidade do Estado de Santa Catarina (UDESC). Bolsista CAPES-DS. Florianópolis - SC - BRASIL igorlemoreira@gmail.com

\section{Para citar esta resenha:}

VALENTE, Heloísa de A. Duarte; PEREIRA, Simone Luci. Com Som, Sem Som - Liberdade políticas, liberdades poéticas. São Paulo: Letra e Voz/FAPESP, 2016. Resenha de: MOREIRA, Lemos Moreira. Canções, Projetos e Expressões Políticas. Revista Tempo e Argumento, Florianópolis, v. 10, n. 24, p. 621 - 627. abr./jun. 2018. 
Capaz de produzir sensações, presenças e despertar sentimentos, a música, entre suas várias possibilidades, é capaz de mobilizar indivíduos e grupos sociais. No Brasil, uma série de pesquisadores, como Marcos Napolitano (2002), Miriam Hermeto (2012) e Márcia Ramos de Oliveira (2002), pontuam a capacidade da música e da canção de não apenas representarem um período vivido, mas também como um caminho de reflexão sobre a opinião pública, a circulação de ideias e seu caráter de mobilização social. É nesse sentido que as pesquisadoras Heloísa de Araújo Duarte Valente ${ }^{1}$ e Simone Luci Pereira ${ }^{2}$ propuseram a organização da obra "Com Som! Sem som... Liberdade políticas, liberdade poéticas", publicada em 2016, pela editora Letra e Voz e dividida em quatro partes.

Fruto de parte das reflexões do $10^{\circ}$ Encontro Internacional de Música e Mídia (2014) $)^{3}$ o livro é a oitava publicação do Centro de Estudos em Música e Mídia (MusiMid), o qual as organizadoras integram. Articulando pesquisas acadêmicas e relatos de experiência, a coletânea reúne pesquisadores/as que fizeram parte da programação do evento com outros/as convidados/as posteriormente, através de um objetivo em comum: refletir acerca das redes de produção e circulação de músicas ibero-americanas entre os séculos XX e XXI através de discussões que gravitassem em torno das relações entre música, mídia, repressão e liberdade.

A primeira parte do livro, Educação dos sentidos. 0 sentido de liberdade..., reune dois textos em torno da noção de liberdade. O primeiro deles, intitulado Arte, criatividade e vida do espírito: 0 que a liberdade de expressão tem a ver com isso?, é assinado pela pesquisadora Daphne Patai, conhecida principalmente por seus estudos na área de História Oral. Em seu texto, a autora faz uma breve reflexão sobre o status da

\footnotetext{
${ }^{1}$ Doutora em Comunicação e Semiótica, Heloísa de Araújo Valente é especialista nas relações entre música, cultura e mídia em perspectiva interdisciplinar, articulando principalmente campos como a comunicação social, a semiótica da cultura e a música. Atualmente, é professora da UNIP, atuando no Programa de PósGraduação em Cultura Midiática, e é fundadora do Centro de Estudos em Música e Mídia.

${ }^{2}$ Doutora em Ciências Sociais, com formação também na área de História, é especialista na área de música, comunicação e antropologia voltada especialmente aos estudos sobre práticas musicais-midiáticas. Atualmente é professora da UNIP, ligada ao Programa de Pós-Graduação em Cultura Midiática, e vicecoordenadora do Centro de estudos em Música e Mídia.

${ }^{3}$ Os Encontros Internacionais de Música e Mídia são promovidos pelo MusiMid anualmente, reunindo pesquisadores e estudiosos dedicados às interfaces entre música e mídia nas mais distintas áreas do conhecimento. Para saber mais: <http://musimid.blogspot.com.br>.
} 
liberdade de expressão na atualidade, tomando como base sua experiência docente. Defendendo a liberdade de expressão, a autora aponta novos grupos e modos de silenciamento desta questão a partir de estudantes que se sentem desconfortáveis em tratar de determinados assuntos. Na visão da autora, a liberdade de expressão teria passado por uma mudança de sentido. Se antes fora alvo de repressão, hoje seria alvo de vigilância por movimentos étnicos e de gênero, especialmente o feminismo, do qual a autora é estudiosa. Já o segundo texto, Tempo de tocar, tempo de cantar, tempo de calar, tempo de inventar: Notas a respeito do percurso da Educação Musical no Brasil, de Marisa Trench de Oliveira Fonterrada, propõe uma análise da história da educação musical no país partindo das relações entre múltiplos tempos e focos do ensino de música nas escolas. Sua abordagem visa, para além de relatar como o ensino foi sendo moldado e, em alguns casos, censurado, destacar a confluência de várias temporalidades no modo de ensinar música no final do século XX e início do XXI.

Intitulada Liberdades políticas e poéticas: A música brasileira, a segunda parte do livro reune três artigos que discutem não apenas a música nacional, mas que dialogam com o plano internacional e/ou global, tomando como fio condutor o universo das linguagens. Lina Noronha, autora de A música como linguagem e os conceitos de música universal e música nacional, discute as relações entre o conceito de música universal e música nacional partindo do pressuposto que a música, enquanto linguagem, não se limitaria apenas ao seu caráter linguístico, mesmo sendo constituída por determinados elementos deste. O foco principal da autora está em analisar a maneira como, no período do "culturalismo", as representações simbólicas da música seriam fundamentais para compreensão de projetos nacionalistas desde romantismo alemão no século XIX.

\section{Em O papel do compositor em debate na imprensa escrita: Brasil, décadas de 1920} a 1960, André Egg dá seguimento à discussão da linguagem musical relacionada a projetos nacionais, porém focando no caso dos compositores. Partindo da imprensa escrita, o autor afirma que mais do que debater a função do compositor, os veículos levantavam a problemática do que isso significava no cruzamento entre as expectativas políticas e as próprias demandas de construção de identidades nacionais em diferentes contextos. Egg parte da preocupação com a utilização de veículos midiáticos na 
compreensão das redes de sociabilidades do ramo musical brasileiro a partir do que poderíamos considerar como um estudo voltado à nova história política (SIRINELLI, 2003). Laan Barros segue as mesmas discussões sobre fontes "impressas" em Sambas de Adoniran em HQ: Narrativas transversais na cultura midiatizada, dando atenção especialmente às Histórias em Quadrinhos impressas e/ou digitais. Partindo da análise de discurso e das representações narrativas, este capítulo foca as questões estéticas de tais obras e seus desdobramentos na percepção inserida no contexto das apropriações e da elaboração de novas representações.

A terceira seção do livro, Liberdades políticas e poéticas ibero-americanas, pode ser considerada como a sua parte mais volumosa em número de textos - um total de cinco. Heloísa Valente abre a seção debatendo uma das principais abordagens da obra: $\mathrm{O}$ viés político da música, dando atenção ao gênero da canção de protesto. Em Grândola, Vila Morena, o povo unido jamais será vencido! A canção de protesto como memória midiática da cultura, Valente se propõe a pensar, a partir de canções dos compositores Sergio Ortega e José Afonso, a importância da música nos períodos de repressão de direitos e de tomada do poder no cenário das ditaduras Chilena e Portuguesa. A análise objetiva pensar de que maneira a canção de protesto, dotada por um forte poder evocativo, é incorporada à memória auxiliando na compreensão de emoções e sentimentos vividos em cada contexto em que ocorreria sua performance. Com foco semelhante, a etnomusicóloga Susana Sardo e o compositor José Mário Branco discutem a canção como dispositivo de militância ideológica em casos brasileiros e portugueses. Intitulado Canções mensageiras: A cumplicidade entre Brasil e Portugal na construção das democracias, o texto versa sobre diferentes composições que circularam, em ambos os países, em seus períodos ditatoriais e também durante sua redemocratização a partir de figuras como Chico Buarque, José Afonso e o próprio José Mário Branco. A especificidade deste texto, que o difere da abordagem de Valente, é centrar a análise em cantores que são compositores de suas canções, o que permitiria investigar uma intencionalidade própria manifestada na criação e articulação entre palavra e sonoridade.

Os três artigos seguintes abordam a música popular especialmente no Uruguai e na Argentina. Marita Bordolli, em seu texto Música Popular, migración, exilio, diáspora: 
uruguay en los siglos XX y XXI, discute as relações entre a música popular uruguaia e os movimentos migratórios, dando foco aos trânsitos culturais frutos dos processos migratórios e da diáspora. Propondo-se a pensar entre múltiplos marcos, pontuando questões desde o século XX, a autora chega até o contexto dos meios digitais, especialmente da web para pensar as músicas uruguaias e latino-americanas em grupos diaspóricos. Mercedes Liska, autora do capítulo Un comunista atípico: Osvaldo Pugliese, um caso paradigmático de censura musical en la Argentina del siglo $\mathrm{XX}$, analisa a trajetória de Osvaldo Pugliese, um dos principais nomes do tango argentino, levantando os processos de censura ao compositor, que foi filiado ao Partido Comunista. Uma das principais contribuições do trabalho é pensar a repressão ao artista, não apenas durante a ditadura militar argentina (1960 e 1970), mas igualmente nas décadas de 1940 e 1950 - no governo populista conhecido como Peronismo.

O último texto da seção, Tecnologías del sonido más allá de la urbe, assinado por Miguel García, alia as temáticas dos dois artigos anteriores. Ao analisar as práticas musicais do povo Pilagá, desde a década de 1950 até a atualidade, o autor transita por conceitos como cena musical e performance, chegando a debater, por exemplo, o contexto da década de 1970 com o crescimento do chamado folklore evangelico. Além disso, García, ao aproximar seu recorte temporal da atualidade propõe que, para o povo Pilagá, a tecnologia tem sido vista como uma extensão da sua música e um espaço de experimentação.

Com som! Sem som... Memórias musicais, em primeira pessoa, última parte da obra, reune dois textos que aliam produção científica e relatos testemunhais. Alfonso Padilha narra sua trajetória durante a ditadura Chilena em La música en una cárcel de la dictadura chilena, especialmente refletindo sobre de que maneira o contexto ditatorial vivido por ele contribuiu para sua visão do potencial político da música. Participante de movimentos comunistas no Chile desde a juventude, e exilado na Finlândia em 1975, Padilla destaca, entre vários pontos, a presença da música dentro dos campos de concentração de presos políticos, criados muitas vezes em estádios de futebol chilenos. Segundo o autor, espaços desse tipo, diferentemente do que se poderia pensar, foram permeados de canções e expressões artísticas inclusive unindo as pessoas ali presas. $O$ 
professor de composição Paulo C. Chagas, apresenta no texto Observar o inobservável: Música e tortura no oratório digital $\boldsymbol{A}$ geladeira um projeto encomendado pelo Centro Cultural de São Paulo e do Núcleo Hespérides em função dos 50 anos do golpe militar de 1965. Seu foco foi o de expressar a memória e experiência do próprio Paulo Chagas que, aos 17 anos, foi torturado no contexto da ditadura civil-militar brasileira. Em seu texto, o autor faz uma análise que busca demonstrar as relações semióticas entre música e denúncias de tortura ao apresentar a sua obra afirmando que a música tem o poder de tornar visível o invisível. De acordo com o autor, a intenção, com A geladeira, foi de dar visibilidade à tortura, porém reconhecendo que a mesma seja impossível de se observar.

De modo geral, os textos reunidos no livro Com som! Sem som...Liberdade políticas, liberdades poéticas buscam trazer um panorama geral da música ibero-americana no final do século XX e início do XXI sob o viés político. Alguns de seus textos observam a canção de protesto, a música dentro dos movimentos sociais e denúncias contra regimes de opressão. Outros adotam perspectivas mais gerais, pensam a função política e social dos indivíduos e da música em sociedade, dando especialmente destaque aos papéis sociais de alguns grupos, como os compositores. Contudo, o que permeia a totalidade deste trabalho é sua contribuição polifônica entre música e mídia, especialmente na compreensão desta última como parte da própria construção de ritmos, carreiras e sujeitos artísticos. Deste modo, a canção não é interpretada na obra apenas como uma expressão de arte por ela mesma, mas que cantar/tocar/compor significa estar permeado por sujeitos, projetos e contextos que são também políticos. 


\section{Referências}

HERMETO, M. Canção popular brasileira e ensino de história: palavras, sons e tantos sentidos. Belo Horizonte: Autêntica, 2012.

NAPOLITANO, Marcos. História \& música: história cultural da música popular. Belo Horizonte: Autêntica, 2002.

OLIVEIRA, Márcia Ramos de. Uma Leitura Histórica da Produção de Lupcínio Rodrigues. Tese de Doutorado - UFRGS, 2002.

SIRINELLI, Jean-François. Os Intelectuais. RÉMOND, René,. Por uma história política. 2. ed. Rio de Janeiro: Ed. da FGV, 2003. 